\title{
RIZICI I POGREŠKE MALIH I SREDNJIH PODUZEĆA U PROCESIMA PROVEDBE EU PROJEKATA
}

\author{
izv. prof. dr. sc. Anamarija Delić \\ Sveučilište Josipa Jurja Strossmayera u Osijeku, Ekonomski fakultet u Osijeku \\ Trg Ljudevita Gaja 7, Osijek, Hrvatska \\ Telefon: 031-224-426 Fax: 031-211-604. E-mail: anamarija.delic@efos.hr \\ Ida Dumančić, student \\ Sveučilište Josipa Jurja Strossmayera u Osijeku, Ekonomski fakultet u Osijeku \\ Trg Ljudevita Gaja 7, Osijek, Hrvatska \\ Telefon: 031-224-426 Fax: 031-211-604. E-mail: po123ida@gmail.com
}

\section{SAŽETAK}

Svaki projekt je izložen raznim vrstama rizika tijekom njegove provedbe koji utječu na uspješnost same provedbe, ali i vjerojatnost ostvarivanja planiranih ciljeva u zadanom vremenskom roku. Pomno analiziranje rizika i kreiranje timova koji imaju dovoljno znanja $i$ iskustva za pravilno provođenje projektnih aktivnosti od presudne su važnosti za uspješnu provedbu projekta. Europski strukturni i investicijski fondovi (ESI) nude mogućnost financiranja projektnih aktivnosti sektoru malih i srednjih poduzeća. Cilj ovoga rada je identificirati najčešće rizike i pogreške vezane uz provedbu projekata u malim i srednjim poduzećima, te dati preporuke za njihovo minimiziranje. Kako bi se dobio uvid u pogreške koje najčešće čine vlasnici malih i srednjih poduzeća u procesu provedbe projekta, provedeno je istraživanje na 52 ispitanika (projektni menadžeri, djelatnici Središnje agencije za financiranje i ugovaranje programa i projekta EU, te djelatnici resornih ministarstava). Istraživanjem su detektirane najveće i najčešće pogreške, ali i izazovi s kojima se susreću vlasnici malih i srednjih poduzeća. Ispitanici iz sektora malih i srednjih poduzeća naveli su i najveće izazove s kojima se susreću tijekom pripreme, ugovaranja i provedbe projekata Europske unije (EU projekata). Rezultati istraživanja upućuju na nužnost jačanja kapaciteta prijavitelja projekata, ali i jače suradnje između prijavitelja i nadzornih tijela.

Ključne riječi: EU projekti; mala i srednja poduzeća; ESI fondovi 


\section{UVOD}

Sektor malih i srednjih poduzeća čini $99,7 \%$ svih poslovnih subjekata u Republici Hrvatskoj, zapošljava 72,7\% svih zaposlenih, izvozi 53\% ukupno ostvarenog izvoza (Alpeza et al, 2019, str. 16.) te se smatra generatorom novih radnih mjesta i zapošljavanja. Sektor malih i srednjih poduzeća ima jednaku važnost u svim članicama EU27 te mu se stoga i poklanja posebna pozornost, a što je vidljivo i kroz Think Small First principle ${ }^{1}$, kojim se prije objave provjerava utjecaj svakog zakona i regulative na navedeni sektor. Kako bi se ovom sektoru omogućio brži rast, ulaganje u novu tehnologiju, a time i konkurentnost, ESI fondovi omogućavaju financiranje projektnih aktivnosti kojima bi se potaknuo brži rast i razvoj ovog sektora. No, unatoč činjenici kako su i hrvatskim malim i srednjim poduzećima dostupna sredstva ESI fondova, provedba projekata, a time i krajnji ciljevi, posebice kada govorimo o konkurentnosti hrvatskog gospodarstva ne daju očekivane rezultate. Prema posljednjem Izvješću o konkurentnosti Svjetskog gospodarskog foruma (Global Competitiveness Report, 2019, str. 15), Hrvatska je na 63. mjestu od ukupno 141 promatrane zemlje. Sama činjenica kako su ispred Hrvatske ostale zemlje iz okruženja ${ }^{2}$, dovoljno govori o konkurentnosti hrvatskog gospodarstva. Investicije kroz ESI fondove na daju očekivane rezultate, a cilj je ovoga rada identificirati najveće prepreke $s$ kojima se susreću vlasnici malih i srednjih poduzeća u procesu prijave i provedbe projekata. S druge pak strane, za potrebe ovog istraživanja anketirani su i ostali dionici ovog procesa (zaposlenici ugovornih tijela te konzultanti koji rade na prijavama i provedbi projekata u malim i srednjim poduzećima) kako bi se utvrdili i nedostatci u navedenim procesima, a koji otežavaju jaču apsorpciju sredstava iz ESI fondova.

\section{RIZICI I NAJČEŠĆE POGREŠKE U PROVEDBI PROJEKATA}

Uspjeh provedbe projekta, kao i faktori koji utječu na sam proces provedbe, definiraju se na različite načine. Baker, Murphy i Fisher (1983) polaze od činjenice kako je za uspjeh projekta presudno jesu li svi stakeholderi (dionici) zadovoljni ostvarenim rezultatima, dok Kerzner (1987) naglašava kako je za uspjeh presudno voditi projekt jednako uspješno kroz čitavo vrijeme trajanja projekta. On naime smatra, kako je najvažnije da sam klijent (korisnik sredstava) bude zadovoljan ostvarenim rezultatima projekta. Prvi autori koji su klasificirali kritične faktore uspjeha projekta su Schultz, Slevin i Pinto (1987) koji su faktore uspjeha podijelili na strateške i taktičke. Ovaj je pristup dalje razvio Kerzner (2001) koji je naveo kako su se faktorima uspjeha u prošlosti smatrali realizirane projektne aktivnosti u predviđenom vremenskom okviru, proračun projekta i sama kvaliteta provedbe projektnih aktivnosti. No, kako navodi ovaj istraživač, uspjehom projekta u novije vrijeme se smatra kada su prethodni navedeni faktori uspjeha ostvareni uz minimalne odmake u poslovnoj kulturi, uz minimalne promjene u novčanom tijeku i uz prihvaćanje svih ostvarenih rezultata samog korisnika. Govoreći o uspjehu projektnog menadžmenta, Baccarini

1 https://ec.europa.eu/commission/presscorner/detail/en/IP_08_1003, pristupljeno 20.06.2020.

2 Prema Izvješću o konkurentnosti za 2019. godinu, Svjetskog gospodarskog foruma, Republika Slovenija je na 35. mjestu, Mađarska na 47. mjestu, Bugarska 49. mjestu, a Rumunjska na 51. mjestu (http://www3.weforum. org/docs/WEF_TheGlobalCompetitivenessReport2019.pdf, pristupljeno 20.6.2020.) 
(1999), Shenhar, Levy i Dvir (1997) navode šest dimenzija uspješnog projektnog menadžmenta: ostvarivanje strateških ciljeva korisnika sredstava, zadovoljstvo krajnjih korisnika i zadovoljstvo svih stakeholdera projekta, uz tradicionalne faktore uspjeha: vremenski okvir, proračun i kvalitetu samog projekta.

Projektni menadžment podrazumijeva i prihvaćanje rizika, koji ukoliko se dogodi, može rezultirati pozitivnim ili negativnim utjecajem na projektne ciljeve (Wysocki i McGary, 2003). Sam projektni rizik najčešće se definira kao nesigurna okolnost koja može nastajati postupno ili odjednom (Omazić i Boljkas, 2005). Svaki je projekt izložen raznim vrstama rizika tijekom svoje provedbe, koji mogu ugroziti provedbu projekta ili dovesti u pitanje ostvarivanje ciljeva projekta. Stoga se sve više pažnje tijekom provedbe projekta poklanja upravo upravljanju projektnim rizicima, a koje uključuje planiranje upravljanja rizicima, prepoznavanje rizika, analizu rizika, plan ublažavanja rizika te nadzor i kontrolu rizika (Wysocki i McGary, 2003; Wysocki, 2019). Učinkovito upravljanje rizicima započinje u najranijoj fazi planiranja samog projekta i provodi se kontinuirano tijekom cijelog životnog ciklusa projekta. U provedbi projekta rizici mogu biti unutarnji i vanjski. Unutarnji rizici su (prema Omazić i Boljkas, 2005): Ijudski potencijali (rizik da jedan ili više članova projektnog tima neće izvršiti svoje projektne obveze prema zadanome planu), tehnološki rizik (rizik da će vijek iskoristivosti projektnog proizvoda biti manji u odnosu na rezultate dobivene studijom izvedivosti), marketinški rizik (rizik da će projektni proizvod ostvariti lošiji plasman na tržištu od očekivanog) te rizik kvalitete proizvoda (rizik da korisnik neće biti zadovoljan projektnim proizvodom). Isti autori definiraju i vanjske rizike: fiskalni izvori rizika, kreditni ili financijski rizik, politički rizik, rizik tržišta radne snage, pravni izvor rizika, meteorološki rizik (kada provedba aktivnosti ovisi o vremenskim prilikama), tehnološki izvor rizika, kulturološki rizik i konkurencija.

Svi navedeni rizici prijete urušavanju projektnih aktivnosti i neispunjavanju zacrtanih projektnih ciljeva, stoga se preporuča, osim provedene analize rizika, proaktivno djelovanje u svakom trenutku provedbe kako bi se rizici, odnosno poteškoće i prepreke na vrijeme uklonile ili barem minimizirale. Za ovakvo djelovanje potreban je kvalitetan projektni tim, a posebice projektni menadžer (Omondi et al, 2005). Kada projektni tim ili pojedini članovi projektnog tima nemaju potrebna znanja nerijetko se događa da projektne aktivnosti kasne, dokumentacija je manjkava, a izvještavanje kasni. Najčešće pogreške, prema Omaziću i Boljkasu (2005) događaju se u postupcima javne nabave te u nepoštivanju ugovornih obveza partnera, a koji vode ka neuspjehu u provedbi projekta i ostvarivanju projektnih ciljeva.

Prema rezultatima istraživanja, provedenim među rumunjskim malim i srednjim poduzećima, korisnicima sredstava EU fondova, najveće prepreke jačoj apsorpciji sredstava predstavljaju (Hunya, 2011; Popa, 2013):

- $\quad$ predug period povrata uloženih sredstava, a što se negativno odražava na novčani tijek korisnika sredstava;

- $\quad$ složene procedure prijave i samog prijavnog obrasca;

- $\quad$ problemi prilikom pronalaska financijskih sredstava za sufinanciranje projektnih aktivnosti;

- $\quad$ složeni procesi javne nabave;

- $\quad$ kriteriji prihvatljivosti za financijsku potporu su restriktivni i nisu u suglasju s ekonomskom aktivnošću, 
- $\quad$ otvaranje i zatvaranje poziva za prijave nisu usklađeni što uzrokuje prekratke rokove za prijave na projektne pozive;

- $\quad$ razdoblje evaluacije projekta, kako je navedeno u samom projektnom pozivu ne poštuje se;

- $\quad$ problemi s novčanim tokom javljaju se uslijed kašnjenja s ocjenom projekta;

- implementacijske procedure nisu jasno definirane

Istraživanje provedeno među malim i srednjim poduzećima u Poljskoj, vezano uz apsorpciju EU sredstava, pokazuje gotovo identične prepreke (Spoz, 2014; Lewandowksa, Stopa i Humeny, 2014). U provedenom istraživanju samo $1 \%$ ispitanih poslovnih subjekata smatra procese prijave na EU projekte jednostavnim, dok čak 38\% smatra ove procese prilično zahtjevnim, a 29\% iznimno zahtjevnim. Za navedene rezultate istraživanja uzroke možemo tražiti i u poznavanju procedura i pravila provedbe EU projekata (Marinescu, 2013). Među ispitanim poslovnim subjektima samo ih $6 \%$ navelo kako imaju sasvim dovoljno znanja kako bi procese prijave i provedbe proveli samostalno. Najčešći razlozi ne prijavljivanja na pozive za financiranje aktivnosti kroz sredstva EU fondova su i među poljskim poslovnim subjektima predugo vrijeme evaluacije projekata, kašnjenje u povratu uloženih sredstava, ograničena fleksibilnost projektnih proračuna, loša kvaliteta usluga koju nude posrednici (konzultanti i savjetnici), birokratske procedure te nedostupne informacije o sredstvima koja stoje na raspolaganju sektoru malih i srednjih poduzeća.

Kao zaključak provedenih istraživanja u obje promatrane zemlje nameće se nužnost prilagođavanja poziva za prijave na projekte sektoru malih i srednjih poduzeća, ažurnim povratnim informacijama u komunikaciji između prijavitelja i ugovornih tijela te dostupnošću konzultanata i savjetnika u procesima prijave i provedbe EU projekata.

\section{METODOLOGIJA ISTRAŽIVANJA}

S ciljem utvrđivanja najčešćih pogrešaka u procesima prijave i provedbe projektnih prijedloga u sektoru malih i srednjih poduzeća u Republici Hrvatskoj, provedeno je istraživanje na 52 ispitanika, koji se bave provedbom projekata financiranih iz sredstava EU - 18 projektnih menadžera, 14 djelatnika ugovornih tijela (Središnje agencije za financiranje i ugovaranje programa i projekata EU, Agencije za plaćanja u poljoprivredi, Hrvatske agencije za malo gospodarstvo, inovacije i investicije (HAMAG BICRO), Agencije za strukovno obrazovanje odraslih i Fonda za zaštitu okoliša i energetsku učinkovitost), 13 djelatnika resornih ministarstava i 7 vlasnika malih i srednjih poduzeća. Istraživanje je provedeno putem upitnika, koji se sastojao i od otvorenih i od zatvorenih pitanja. Kako bi se utvrdili stavovi sektora malih i srednjih poduzeća u Republici Hrvatskoj prema sredstvima iz EU fondova koji im stoje na raspolaganju, proveden je i dubinski intervju s poslovnim subjektom iz navedenog sektora koji se u nekoliko navrata koristio sredstvima ESI fondova. Iskustva i stajališta vlasnika i projektnog menadžera iz intervjuiranog poslovnog subjekta bili su vodilja pri kreiranju upitnika. U konačnici, dobiveni rezultati istraživanja komparirani su s rezultatima i stajalištima sektora malih i srednjih poduzeća u Rumunjskoj i Poljskoj. Na osnovu dobivenih rezultata oblikovan je zaključak te su dane preporuke za jačanje apsorpcijskog kapaciteta sektora malih i srednjih poduzeća i optimalno korištenje sredstava ESI, ali i ostalih EU fondova. 


\section{REZULTATI ISTRAŽIVANJA}

Rezultati provedenog istraživanja upućuju ponajprije na nedovoljno poznavanje metodologije financijskog praćenja provedbe projekata.

Tablica 1. Poznavanje metodologije financijskog praćenja među ispitanicima

\begin{tabular}{|l|c|c|c|}
\hline & Potpuno & Djelomično & Nedovoljno \\
\hline $\begin{array}{l}\text { Poznavanje financijskog praćenja provedbe projekta } \\
\text { među korisnicima EU sredstava }\end{array}$ & $7,69 \%$ & $53,85 \%$ & $38,46 \%$ \\
\hline
\end{tabular}

Izvor: Provedeno istraživanje

Kako je u upitniku ostavljena mogućnost i komentara na postavljeno pitanje, zanimljiva su razmišljanja ispitanika:

„Korisnici su najupućeniji u ovaj aspekt provedbe, budući da im svaka kuna neprihvatljivog ili nepriznatog troška može predstavljati katastrofu za proračun. To se posebno odnosi na udruge i poduzetnike."

„Pitanje je uvreda za većinu korisnika sredstava. Najmanje su upućeni djelatnici županija, razvojnih agencija i sličnih proračunskih korisnika koji nemaju osjećaj za javna sredstava."

Upitnikom su se željeli ispitati i stavovi i iskustva korisnika EU sredstava o preprekama na koje nailaze u procesima prijave i provedbe projekata.

Tablica 2. Prepreke uspješne provedbe EU projekata financiranih iz ESI fondova u Hrvatskoj

\begin{tabular}{|l|c|}
\hline Prepreke u procesima prijave i provedbe EU projekata & Učestalost \\
\hline Nepoznavanje pravila provedbe javne nabave u okviru provedbe projekta & $55,77 \%$ \\
\hline Nedovoljno poznavanje pravila o provedbi projekta & $42,31 \%$ \\
\hline $\begin{array}{l}\text { Nepoznavanje pravilnog računovodstvenog evidentiranja i financijskog praćenja provedbe } \\
\text { projekata }\end{array}$ & $34,62 \%$ \\
\hline Nedovoljni kapaciteti financijskih djelatnika korisnika sredstava & $32,69 \%$ \\
\hline Složenost postupaka u provedbi projekata & $30,77 \%$ \\
\hline Nedovoljni kadrovski kapaciteti djelatnika javne nabave & $26,92 \%$ \\
\hline Nedovoljni kapaciteti voditelja projekata u malim i srednjim poduzećima & $11,54 \%$ \\
\hline
\end{tabular}

Izvor: Provedeno istraživanje

Najsloženiji dio provedbe projekta je, prema mišljenju ispitanika, provedba postupka javne nabave $(66,67 \%)$ te financijsko praćenje projekta, dok su osiguranje promidžbe i vidljivosti najjednostavniji dijelovi u procesu provedbe projekta. Prema ponderiranim prosjecima svih odgovora, najviše problema u provedbi korisnici imaju s postupcima javne nabave, financijskim praćenjem projekta, financijskim i narativnim izvještavanjem, provedbom aktivnosti, koordinacijom dionika projekta te promidžbom i vidljivošću. 
Među najveće pogreške koje korisnici sredstava čine, ispitanici su naveli puno različitih stajališta, a sukladno svojim iskustvima tijekom provedbe projekata: loše vremensko planiranje projekata, loše računovodstveno evidentiranje projekta, premalo timskog rada, loša koordinacija projektnih partnera, umiješanost politike u provedbu projekata, olako shvaćanje projekta i projektnih aktivnosti, loše planiranje, nepridržavanje ugovornih odredbi, neažurni javni službenici i dr.

Najčešći razlozi dodjele financijskih korekcija vezani su uz procese i postupke javne nabave: pogreške u provedbi javne nabave, neostvarenje pokazatelja, nedostatak pravovremenih preporuka, nepoštivanje ugovora o dodjeli sredstava, korištenje sredstava mimo ugovornih odredbi, prestroga kontrola, prekasna konzultacija s voditeljima projekata. Vezano uz financijske korekcije, bilo je zanimljivo provjeriti i koje su najčešće dodijeljene financijske korekcije korisnicima sredstava. Najčešća financijska korekcija je 5\% (48,97\% ispitanika), dok je njih najmanje imalo 100\%-tnu financijsku korekciju (4,08\%).

Posljednje pitanje u upitniku odnosilo se na preporuke kojima bi se povećala uspješnost provedbe projekata. Među najčešćim odgovorima su bili:

- $\quad$ edukacije o javnoj nabavi, računovodstvu i provedbi projekata;

- više komunikacije s ugovornim tijelom;

- detaljno proučavanje ugovora o dodjeli sredstava;

- više timskog rada i stručnih djelatnika u timu;

- $\quad$ angažman adekvatnih osoba za provođenje procesa javne nabave;

- $\quad$ angažiranje konzultanata i savjetnika.

U dubinskom intervju, provedenim s poslovnim subjektom koji je u nekoliko navrata koristio sredstva EU fondova, također saznajemo kako ključnim uspjehom u prijavi i provedbi projekata smatra dobro poznavanje pravila i procedura projektnog menadžmenta. Naime, član obitelji koji je aktivno uključen u poslovanje bivši je zaposlenik jednog ugovornog tijela. Navedeni poslovni subjekt zaposlio je računovođu na puno radno vrijeme te odlučio, barem za trajanja projekta, imati pod konstantnim nadzorom sve računovodstvene i financijske evidencije. Računovođa je u poslovnom subjektu, zajedno s voditeljem projekta, bio zadužen i za poslove financijskog izvještavanja, a u što je uvelike ubrzalo same procedure izvještavanja i povrata uloženih sredstava. Svi navedeni čimbenici omogućili su vlasniku poslovnog subjekta maksimalno iskorištavanje bespovratnih sredstava, širenje poslovnog subjekta na tržište izvan Republike Hrvatske, novo zapošljavanje i podizanje razine konkurentnosti. No, kako navode u poslovnom subjektu, ključno je bilo poznavanje pravila projektnog menadžmenta i ažurna komunikacija s ugovornim tijelom.

Slijedom navedenih rezultata istraživanja, može se zaključiti kako u sve tri promatrane zemlje vlasnici malih i srednjih poduzeća navode iste prepreke u jačoj apsorpciji sredstava iz EU fondova:

- $\quad$ složene procedure prijave i provedbe projekata

- $\quad$ složeni procesi javne nabave

- pretjerana birokracija

- $\quad$ kašnjenje u povratu uloženih sredstava

- $\quad$ predugo vrijeme evaluacije projekata 
- $\quad$ nedostatak informacija o dostupnim EU sredstvima

- $\quad$ nepoznavanje pravila i procedura projektnog menadžmenta

U tri promatrane zemlje, jedino se u Poljskoj vlasnici malih i srednjih poduzeća žale na loše usluge vanjskih savjetnika (savjetnika i konzultanata za EU projekte), dok u Hrvatskoj i Rumunjskoj vlasnici malih i srednjih poduzeća nisu toga stava.

\section{ZAKLJUČAK}

Temeljem istraživanja na sektoru malih i srednjih poduzeća u Rumunjskoj, Poljskoj i Hrvatskoj te istraživanja koje je provedeno i s ključnim dionicima u Hrvatskoj, može se zaključiti kako su procedure i pravila projektnog menadžmenta među najvećim preprekama njihove jače uključenosti u korištenje sredstava iz EU fondova za jačanje svog konkurentnog položaja. Procesi javne nabave, koji su neizostavni dio gotovo svakog projekta financiranog iz ESI sredstava su složeni i dokumentacijski zahtjevni, što predstavlja dodatnu nepoznanicu u malim i srednjim poduzećima. Kako bi se projekti prijavili na bespovratna sredstva iz EU fondova nužno je osigurati i sufinanciranje, a što u velikom broju slučajeva zahtjeva vanjsko financiranje, odnosno financiranje sredstvima izvan poduzeća. U tim situacijama iznimno je važno da poslovne banke prate svoje komitente te odobravaju kratkoročna sredstava za financiranje projektnih aktivnosti. S druge pak strane, za povrat uloženih sredstava važno je i ažurno izvještavanje korisnika sredstava, ali i povratnih informacija ugovornih tijela. Može se zaključiti kako su pravila i procedure projektnog menadžmenta ključne za korištenje bespovratnih sredstava iz EU fondova, a u čemu vlasnicima malih i srednjih poduzeća najčešće pomažu vanjski stručnjaci, odnosno privremeno angažirani savjetnici ili konzultanti. Neke od navedenih prepreka je nužno mijenjati na razini EU27, dok je druge, ponajprije one koje se odnose na znanja i informacije moguće ublažiti na nacionalnoj razini. Mreža savjetnika ili konzultanata koji se uključuju u prijavu i provedbu projekata doprinosi većoj apsorpciji bespovratnih EU sredstava na razini sektora malih i srednjih poduzeća, no nužno je osigurati kvalitetne savjetnike koji dobro poznaju projektni menadžment, rizike i izazove koje prijava i provedba projekata nosi sa sobom.

S ciljem minimiziranja identificiranih prepreka na strani korisnika, no i najčešćih grešaka u procesima prijave i provedbe projekata (prema mišljenju ispitanika iz ugovornih tijela), nužno je osigurati edukaciju i informiranje, savjetnike koji bi pratili procese provedbe projekata, ali i sufinanciranje njihovih usluga. Procedure prijave projekata, koje su u sve tri promatrane zemlje ispitanici naveli kao najveću prepreku nije moguće mijenjati na razini Hrvatske, a sufinanciranjem usluga savjetnika i lobiranjem na razini Europske unije i procesi prijave projekata mogli bi postati jednostavniji krajnjim korisnicima bespovratnih sredstava. 


\title{
RISKS AND MISTAKES OF SMALL AND MEDIUM-SIZED ENTERPRISES IN IMPLEMENTATION OF EU PROJECTS
}

\author{
Anamarija Delić, PhD \\ Josip Juraj Strossmayer University of Osijek, Faculty of Economics in Osijek \\ Trg Ljudevita Gaja 7, Osijek, Croatia \\ Telephone: 031-224-426 Fax: 031-211-604. E-mail: anamarija.delic@efos.hr \\ Ida Dumančić, student \\ Josip Juraj Strossmayer University of Osijek, Faculty of Economics in Osijek \\ Trg Ljudevita Gaja 7, Osijek, Croatia \\ Telephone: 031-224-426 Fax: 031-211-604. E-mail: po123ida@gmail.com
}

\begin{abstract}
Each project is exposed to various types of risks during its implementation, which affect the success of implementation itself, as well as the probability of achieving the planned goals within the given timeframe. Careful risk analysis and creation of teams with sufficient knowledge and experience to properly execute project activities are essential for successful project implementation. European Structural and Investment Funds (ESI) offer the possibility to finance project activities in the small and medium-sized enterprise sector. The aim of this paper is to identify the most common risks and mistakes related to the implementation of projects in small and medium-sized enterprises, and to provide suggestions for their minimisation. In order to gain insight into most common mistakes made by the owners of small and medium-sized enterprises in the project implementation process, a survey was conducted on 52 respondents (project managers, employees of the Central Finance and Contracting Agency, and employees of line ministries). The survey identified the biggest and most common mistakes, as well as the risks that owners of small and medium-sized enterprises face. Respondents from the small and medium-sized enterprise sector also outlined the greatest challenges they face in preparing, contracting and implementing European Union's projects (EU projects). The results of the survey indicate the need for strengthening the project applicants' capacity, as well as the need for closer cooperation between the applicants and supervisory bodies.
\end{abstract}

Keywords: EU projects; small and medium-sized enterprises; ESI funds 


\section{LITERATURA}

1. Alpeza, M., Has, M., Oberman, M., Oberman Peterka, S., Perić, J., Pervan, J., Šimić Banović, R. (2019). Izvješće o malim i srednjim poduzećima u Hrvatskoj - 2019. uključujući rezultate GEM - Global Entrepreneurship Monitor istraživanja za Hrvatsku za 2018. godinu. Zagreb: CEPOR.

2. Baccarini, D. (1999). The logical framework method for defining project success. Project management journal, vol. 30(4), 25 - 32.

3. Baker, B. N., Murphy, D. C., Fisher, D. (1983). Project Management Handbook: Factors affecting project success. New York: Van Nostrand Reinhold.

4. European Commission: „Think Small First": A Small Business Act for Europe. Preuzeto s https:// ec.europa.eu/commission/presscorner/detail/en/IP_08_1003 (20.6.2020.)

5. Hunya, G. (2011). Problems of Romanian SMEs with tapping EU structural funds. Eastern Journal of European Studies, 2(1), $129-146$.

6. Kerzner, H. (1987). In search of excellence in project management. Journal of Systems Management, 38(2), $30-39$.

7. Kerzner, H. (2001). Project Management: A System Approach to Planning, Scheduling and Controlling (7th Ed.). New York: Wiley\&Sons.

8. Lewandowska, A., Stopa, M., Humeny, G. (2014). The European Union Structural Funds and Regional Development: the Perspective of Small and Medium Enterprises in Eastern Poland. European Planning Studies, 23(4), 785 - 797.

9. Marinescu, N. (2013). The process of attracting EU funds by SMEs: Lessons from the past. Studia Univesitatis Babes Bolyai - Negotia, 58(4), 53 - 67.

10. Omazić, M., Baljkas, S. (2005). Projektni menadžment. Zagreb: Sinergija.

11. Omondi, R., Munevar, J., Piparo Liljegren, C. L, Nappini, F., Soeltenfuss, J. (2005). Vodič kroz fondove Europske unije: pristup najvećem europskom donatoru. Zagreb: Nacionalna zaklada za razvoj civilnog društva.

12. Popa, A. (2013). Performance indicators for SMEs Accesing EU Funds. Constanta Maritime University Annals XIV, 19, $319-322$.

13. Schultz, R. L., Slevin, D. P., Pinto, J. K. (1987). Strategy and tactics in a process model of project implementation. Interfaces, 17, $34-46$.

14. Schwab, K. The Global Competitiveness Report 2019, World Economic Forum. Preuzeto s http:// www3.weforum.org/docs/WEF_TheGlobalCompetitivenessReport2019.pdf, (20.6.2020.)

15. Shenhar, A., Levy, O., Dvir, D. (1997). Mapping the dimensions of project success. Project Management Journal, 28(2), 5 - 13.

16. Spoz, A. (2014). Significance of the EU Funds in Investments of Small and Medium-Sized Enterprises. Oeconomia Copernicana, 5(4), $61-74$.

17. Vela, A. (2015). Menadžment ESI fondova. Zagreb: Školska knjiga.

18. Wysocki, R. K. (2019). Effective Project Management: Traditional, Agile, Extreme, Hybrid (7th Ed.). New York, USA: Willey\&Sons.

19. Wysocki, R. K., McGary, R. (2003). Effective Project Management ( $3^{\text {rd }}$ Ed.), Indianapolis, USA: Willey. 